Journal of Machine Engineering, 2022, Vol. 22. No. 1, 25-42

ISSN 2391-8071 (Online)

Received: 27 September 2021 / Accepted: 12 January 2022 / Published online: 25 January 2022

manufacturing, reduce, recycle, reuse, reborn, re-extension, Double-Eco model, Eco-friendly, lubrication, thermal deformation, forced cooling

Ikuo TANABE ${ }^{1,2^{*}}$

\title{
APPLICATION OF THE PENTAGONAL W-ECO MODEL FOR MANUFACTURING BASED ON "SDGs"
}

\begin{abstract}
The Sustainable Development Goals (SDGs) were proposed to ensure the well-being of everyone on earth, a purpose to which all the fields, including manufacturing, must contribute. However, although industry is implementing this laudable concept in a piecemeal fashion, it is currently unlikely to achieve all 169 targets in the 17 Goals by the SDG deadline of 2030. Therefore, qualitative and quantitative achievement indicators and effective evaluation methods are needed to achieve the 17 goals of the SDGs when developing industrial products. Therefore, in this study, the manufacturing in response to the 17 goals and the 169 targets of the SDGs is considered, and the application of the pentagonal W-ECO model for manufacturing based on the SDGs was proposed. First, the current situation of manufacturing was considered from an environmental perspective, which is also important for the SGDs. Secondly, product's lifespan which is deeply related to the environment, was discussed in terms of the correlation between time, technology and environment, and "Re" technology was proposed to extend product's lifespan and save resources. Then three cases of development for environmental conservation were introduced to understand the current situation, and it was confirmed that the new technologies in the three cases can contribute to the achievement of SDGs, however the degree of their contribution couldn't be evaluated quantitatively. Finally, the previous three cases using the proposed pentagonal W-ECO model quantitatively evaluated and confirmed that the results of the evaluation provide a quantitative indicator for achieving the SDGs. As a result, the effectiveness of the pentagonal W-ECO model for manufacturing based on SDGs is evaluated.
\end{abstract}

\section{INTRODUCTION}

The SDGs are the United Nations' international goals for sustainable development. They consist on 17 global goals and 169 targets (achievement criteria). According to the Ministry of Foreign Affairs of Japan [1]: "The SDGs were produced by the Millennium Development Goals (MDGs) in 2001 and later adopted as the 2030 Agenda for Sustainable Development at the UN Summit in September 2015, declaring international goals for a sustainable and better world by 2030". The main pledge of SDGs is to "leave no one behind" on the planet. In fact, the SDGs' strategy is universal as it focuses not only on the developed countries but on the developing countries as well. Today, in Japan, all the fields are aiming to achieve the SDGs. The SDGs are presented in Fig. 1 [2]. The goals directly related to manufacturing are: No. 7:

\footnotetext{
${ }^{1}$ Department of Mechanical Engineering, Nagaoka University of Technology, Japan

${ }^{2}$ School of Engineering, Sanjyo City University, Japan

*E-mail: tanabe@mech.nagaokaut.ac.jp / tanabe-ikuo@ sanjyo-u.ac.jp https://doi.org/10.36897/jme/145758
} 
Affordable and clean energy, No. 12: Responsible consumption and production, No. 13: Climate action, No. 14: Life below water and No. 15: Life on land. To evaluate the current state of manufacturing in regard of SDGs, it is important to focus on those targets, but, since the final users of manufacturing are the humans, the manufacturing should be optimized while considering the other targets.

All humans must have the right to become Ladies and Gentlemen, live in harmony and share the resources together. Also, the earth should be considered as our friend and should be protected and respected.

Those who are involved in manufacturing should take into account what they have do to contribute to the achievement of SDGs. For instance, in research and development, it is important to maximize the gain, obtain high added value and optimal characteristics, but it is also necessary to evaluate the processing time, the running cost and the $\mathrm{CO}_{2}$ emission, and thus contribute to the achievement of SDGs.

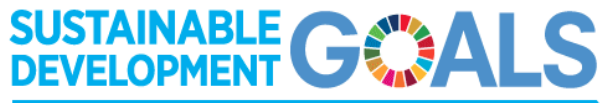 17 GOALS TO TRANSFORM OUR WORLD}

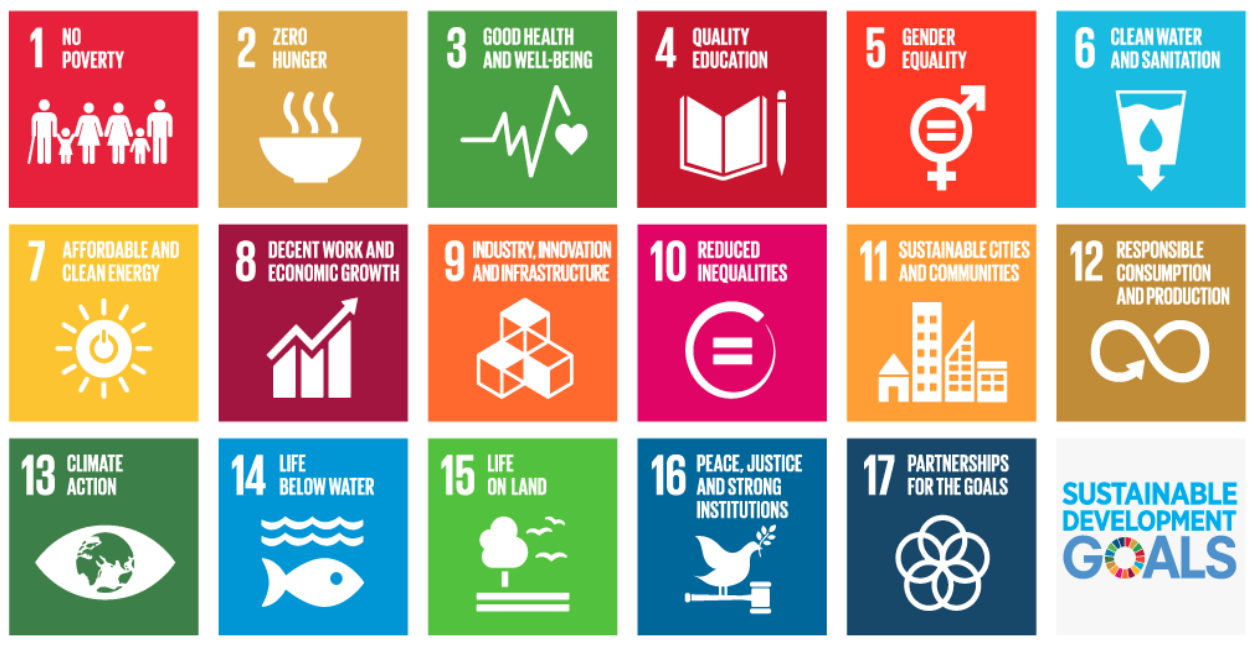

Fig. 1. 17 goals for a sustainable and better world [2]

This section describes the current state of manufacturing from an environment protection's perspective. The industrial world is continuously evolving and as a result, the devices are changing as well as the processes, techniques and strategies. The impacts of those changes on humans are important because they help them adapt to the changes of the environment. In this regard, industries are putting big efforts to improve their performances, however, this doesn't come without a cost which is usually the environment. The reason why, finding a compromise between the technical aspect of technologies and their environmental impacts is now being taken more seriously. However, the industries' growth rate is very high and it is exceeding the environmentally friendly approaches. Therefore, there is a need to develop sustainable products in order to slow down the growth of technologies and allow the environmental approaches to be more efficient. Nevertheless, the idea of sustainable products 
is still not appreciated by the manufacturers because it is usually seen as a drop of the financial gains, it requires a change in the production and marketing strategies etc.

There are many different ways of evaluating technologies [3] including the design process "ecology-economy-equity" fractal triangle suggested by McDonough (2006). Although most of the current evaluation methods are flexible for future stages, they are, most of the time, only focusing on the cost or performances due to profit issues. It is noted that there is a need to adapt comprehensive method that takes into consideration the lifespan, the ecology aspect and the safety. To achieve a competitive technology, the same degree of priority should be given to all the mentioned parameters. To improve the performances while considering the cost and the environmental impact, an evaluation platform called the "W-ECO Model" was developed; this platform provides an evaluation of the system as a whole while exploring alternatives for performance improvements [4]. The evaluations approaches of each parameter of the W-ECO model were discussed in previous studies [5], [6] and in another research [7], a flexible framework proposing an evaluation method that makes a transition from a focus on environmental friendliness to an improved eco-efficiency definition was introduced. In that research, the "DE Index", a dimensionless evaluation index based on the current methodologies was introduced. Also, in a more recent study, the Risk evaluation and lifespan evaluation were added to the W-ECO model [8] and the new model was applied to a machine tool lubrication technology as a case a study.

As for the research on manufacturing to achieve the SDGs, explained in Chapter 2, wideranging researches such as environment [9-12], life cycle [9], [13-15], disposal [9], [16-18] and recycling [16-20]. These are some of the studies that have been carried out on manufacturing from Industry 1.0 to Industry 4.0 [21], [22] and beyond, including zero defect manufacturing [23-25] and the impact of Industry 4.0 on the industry [26-28]. However, there are no methods or indicators to evaluate the manufacturing quantitatively and comprehensively based on the SDGs, and it is difficult to set appropriate target values for each goal while considering the overall sustainability to achieve the SDGs.

Therefore, in this paper, in Chapter 2, the interactions between time and technology, technology and environment, and time and environment are discussed, using the computer's lifecycle of computers an example. The necessity of the "regeneration" technology for the manufacturing based on the SDGs is also discussed. Then, in Chapter 3, three examples from the author's previous work are presented, and their relationship with the SDGs is discussed. Then, in Chapter 4, the three examples are quantitatively evaluate using the W-ECO model also proposed by the author in his past researches. Also, the effectiveness of using the W-ECO model as a quantitative evaluation method for manufacturing to achieve the SDGs is considered, and proposed as one of the manufacturing methods to achieve the SDGs.

\section{PRODUCT'S LIFESPAN EXTENSION AND REGENERATION TECHNOLOGIES FOR ACHIEVING THE SDGs}

In this chapter, the life cycle of industrial products, and the importance of achieving the SDGs during the life cycle discussed. Using computers as an actual example [8], lifespan and life cycle are discussed from the perspective of time, technology and environment as well as 
from the perspective of users, manufacturers and governments. Then the longevity and recycling technologies for the SDGs are briefly discussed. For more detail information on this, please refer to the author's previous papers [8].

(1) Interrelationship between Time and Technology

In Information and Communication Technology (ICT), temporality, acceleration and simultaneity are important [29]. Unfortunately, the lifespan of the products used is neglected. Recently, however, industry and governments have begun to consider environmental issues from a lifecycle perspective [30]. For example, the lifespan of a PC has a significant impact on energy use, disposal, prediction of sustainability (in e-waste), management strategies and policies [31]. For example, a lifecycle approach can help to decide whether to dispose or reuse [16]; the lifecycle of a single PC can include many different scenarios [13]. Also, its lifespan may differ significantly from the actual period of its use [13-15]. Existing studies, policy forecasts and LCAs almost without exception consider a constant lifetime for computers and related products. However, the assumption of constant lifetime has been considered problematic and a new lifespan approach has been proposed for practical application [31].

(2) Interrelationship between Technology and Environment:

There are many potential environmental problems associated with computers; for example, the disposal of toxic elements, chemicals and plastics, the amount of energy, fossil fuels, natural resources and water consumption [14]. The environmental impact of their transport is also considerable. For them, traditionally, only the problem of waste disposal was considered. In contrast, in many countries, recycling has been considered the most effective solution to deal with E-Waste. Recycling discarded computers in a resource-efficient manner is a major challenge [32]. Although one part of the computer is recycled, it does not cope with the huge amount of waste to be recycled [29]. Semiconductors are destroyed in the recycling process and are not recovered [17]. Although existing WA waste management models include recycling, they do not take into account important items such as the energy consumption of raw material extraction, production, use and disposal [30]. Thus, even if ICTs are properly disposed of, recycled and returned to the market in the form of products, their environmental and health risks are not controlled [29]. Another issue is that as recycling becomes more economically viable, the price of raw materials falls, resulting in increased productivity and the creation of more waste [29]. In response, it is important to evaluate the environmental impact of the product in a life cycle assessment [30]. This LCA takes into account all stages from use to disposal (raw material extraction, production, manufacturing, distribution and transport). The life cycle energy use of computers is dominated by production (81\%) compared to operation (19\%). Therefore, extending the life of lifespan is crucial to reduce not only the energy impact associated with production and disposal, but also other environmental impacts [33].

(3) Interrelationship between Time and Environment.

Electrical and electronic products have a very short economic life cycle and become obsolete very quickly. The high demand for computers and mobile phones in particular has led to an increase in the volume of their waste. The innovation cycle of these devices is becoming shorter and shorter, accelerating their replacement and creating an increase in e-waste. The improper disposal of this has a major impact on the environment [18]. Similarly, this impact also includes the unconscious behaviour of users (e.g. long storage without use, power 
on without use). In response, the ideal scenario is reuse, recycling and proper disposal in order to minimize the environmental impact. As far as waste is concerned, it is desirable for the lifecycle to be as long as possible [14], [16]. Obstacles to recycling include security constraints, used PC market constraints, and transfer constraints of pre-installed software licenses to secondary owners [9], [18]. Thus, considering all the environmental impacts of personal computers and ICTs from consumed natural resources, solid wastes, hazardous materials and the above constraints, the lifespan of ICTs in general is shortened. it can be concluded that ICTs are not only about speed and performance, but also about longevity.

(4) "RE" Technology.

The 3R, an abbreviation of "Reduce", "Reuse" and "Recycle", is known as a concept aiming to conserve the natural resources and protect the environment [16], [18-19], [29]. "Reduce" refers to the reduction of used resources and generated waste. It also includes providing durable products and designing maintenance systems to extend the lifespan of products. "Reuse" means the repeated use of products and their components. This can be achieved through the supply of reusable products, the development of repair and diagnostic techniques, and remanufacturing. "Recycle" is the effective use of waste as a raw material or energy source. This can be achieved by designing products, recovering used products and developing recycling technology and equipment.

The concept of 3R is extended to include the notions of "Reborn" and "Re-extension" and become 5R (Fig. 2). "Reborn" refers to the transformation of a second-hand product into a new product. It is an active modification that aims to increase the performances, precision and functionality. It is faster, cheaper and more resource-conserving than producing new items. "Re-extension" means that the user consciously extends the usage period by maintaining the product's functionality, accuracy, quality and value at a high level for a long period of time. "Re-extension" requires the awareness and involvement of the products' users. For users accustomed to casual disposability, unplanned mass consumption and casual disposal, this "Re-extension" is an extremely important mission to achieve the SDGs.

Reduce : Resource saving, Reduce of waste produced, Zero emissions, Providing products with high durability and Maintenance system to extend product life.

Reuse : Repeated use, Reusable products, and Repair and diagnostic techniques, Re-manufacturing

Recycle : The effective use of waste as a raw material or energy source. The design of products, the recovery of used products and the development of recycling technology and equipment to make this possible.

\section{R Technology}

Reborn : Development of products with a higher load than before recycling, recycling at new product level

Re-extension : Strong awareness of environmental friendliness and extending life expectancy for the SDGs

5 RE Technologies

Fig. 2. 5 RE Technologies (Stong awareness by manufactures and all users is necessary

"Reuse", "Recycle" and "Reborn" require new materials and electric energy, which can be a new detriment to achieve the SDGs. In the other hand, "Reduce" and "Re-extension" 
require a high level of technology in the development phase. As they do not require new materials or electric energy, they are effective to achieve the SDGs.

As described above, users, manufacturers, and the government can cooperate to extend the lifespan of industrial products and implement recycling technology (3R, 5RE technology) to achieve resource conservation, energy conservation, and environment protection, which is very important for manufacturing based on the SDGs.

\section{THREE EXAMPLES FOR QUANTITATIVE EVALUATION USING THE PENTAGONAL W-ECO MODEL}

In this Chapter, two examples of the author's previous work [33, 34] are introduced in Sections 3.1. and 3.2., and new example is also described in Section 3.3, and the relationship between those examples and the SDGs is discussed in Section 3.4. These are the examples of the quantitative assessment using the Pentagonal W-ECO model for manufacturing based on the SDGs in the next chapter. In order to evaluate the environment protection effect of these cases, the calculation method of emission is explained.

The resources' conservation and the carbon-neutral are essential for a manufacturing process contributing to the SDGs achievement. The $\mathrm{CO}_{2}$ emission from the use of electrical energy should be evaluated. The $\mathrm{CO}_{2}$ emission $\mathrm{CLCO}_{2}\left[\mathrm{~kg}-\mathrm{CO}_{2}\right]$ due to the energy consumption is calculated using the equation (1) [20],

$$
\mathrm{CLCO}_{2}=0.496 \times W E
$$

where, $W E$ is the consumed electric power [W] and $0.496[\mathrm{~kg}-\mathrm{CO} 2 / \mathrm{kWh}]$ is the ratio between the used electric power and the $\mathrm{CO}_{2}$ emission [30]. The $\mathrm{CO}_{2}$ emission $C L C O_{2} \quad\left[\mathrm{~kg}-\mathrm{CO}_{2}\right]$ due to manufacturing oil consumption for lubrication or forced cooling is calculated using the equation (2) [11],

$$
C L C O_{2}=D \times C \times Q \times 44 / 12
$$

where, $D$ is the quantity of discharge oil $[\mathrm{k} \ell], C$ the calorific value $[\mathrm{GJ} / \mathrm{k} \ell], Q$ the carbon dioxide emissions factor for oil [t-C/TJ]. Here, $C=40.2 \mathrm{GJ} / \mathrm{k} \ell$ and $Q=19.9 \mathrm{t}-\mathrm{C} / \mathrm{TJ}$ [12].

In order to achieve the SDGs, the new products must be resource-saving, oil-free and energy-saving. Therefore, in this section, three ideas are developed for the carbon-neutral.

\subsection{DOUBLE-ROLLERS ARRANGEMENT \& COST-EFFECTIVE AND ECO-FRIENDLY PERMANENT GREASE FOR MACHINE TOOL SLIDERS}

The first example is "THE DOUBLE-ROLLERS ARRANGEMENT \& COSTEFFECTIVE AND ECO-FRIENDLY PERMANENT GREASE FOR MACHINE TOOL SLIDERS" [34]. The double-rollers arrangement, presented in Fig. 3 is designed to collect, distribute and adjust the thickness of the grease throughout a machine tool slide. It consists 
of two outer rollers used to hold the grease and two inner rollers used to control and adjust the grease thickness on a guideways surface. The arrangement also contains bolts and springs used to adjust the load. As lubricant for this experiment, the polyisobutylene (PIB: polymer) is mixed in the lubricant. The optimum conditions for operation are explored using the Taguchi method, and the lubrication properties are evaluated experimentally. The acceptable thickness of the grease lasts $10 \mathrm{~h}$ for the conventional lubrication, $80 \mathrm{~h}$ for the rollers under the worst conditions and $1948 \mathrm{~h}$ under the best conditions. The evolution of the grease thickness during the experiments is presented in the thickness during the experiments is presented in the Fig. 4.

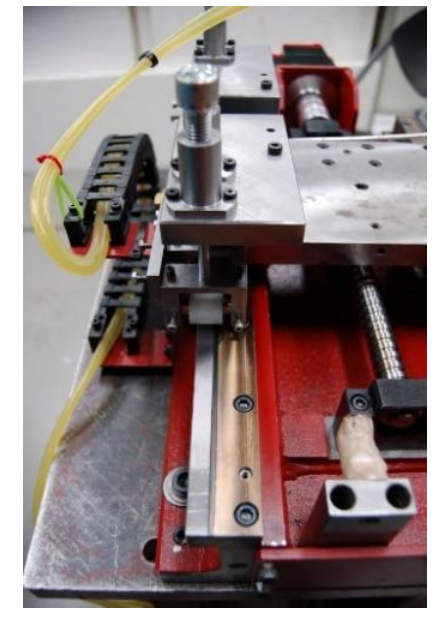

a) Photograph of the arrangement

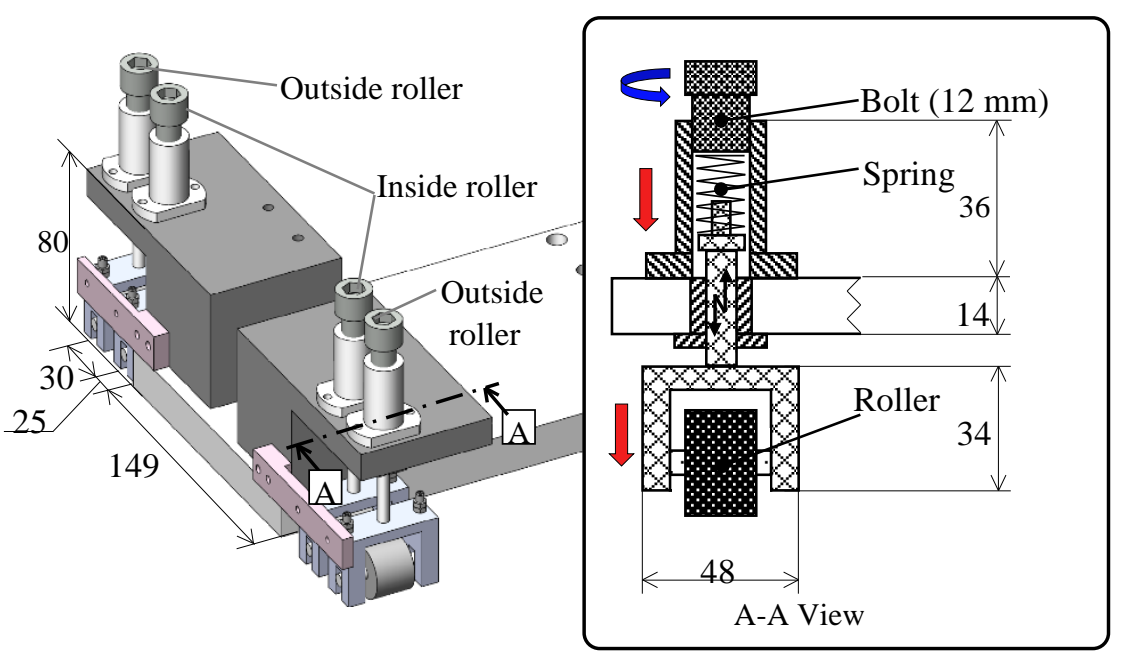

b) Arrangement's schematic view

Fig. 3. Double-roller arrangement for the machine tool lubricant distribution [33]

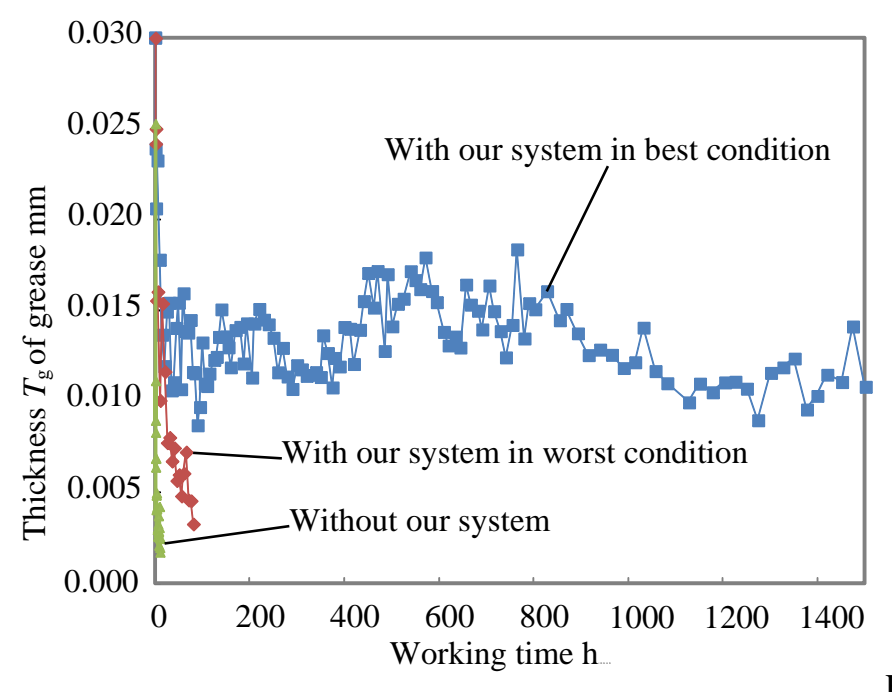

Fig. 4. Grease thickness variation throughout time under different lubrication methods [33]

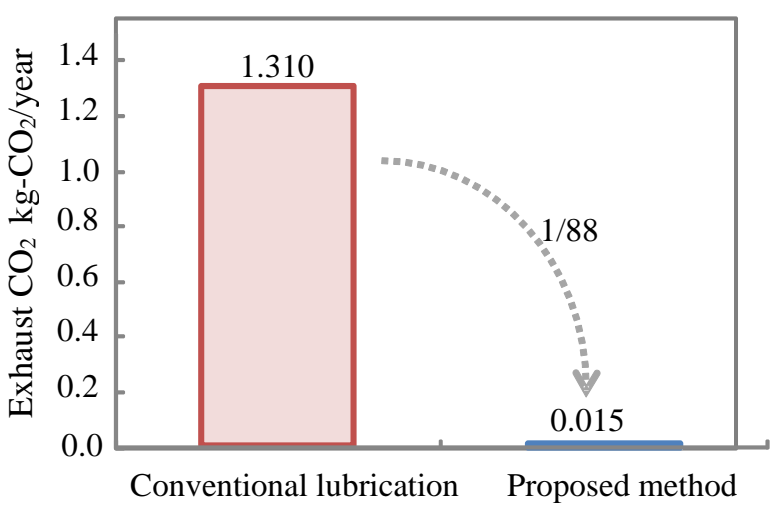

Fig. 5. Comparison of exhaust $\mathrm{CO}_{2}$ regarding the proposed permanent lubrication and the conventional lubrication [33]

The exhaust $\mathrm{CO}_{2}$ with the proposed lubrication is shown in Fig. 5. Compared to the conventional method, the exhaust $\mathrm{CO}_{2}$ is reduced to $1 / 88$. The proposed method reduces 
the coefficient of friction to 0.07 and is effective for the environmental protection and cost reduction. The main advantage of this technology is that the lifespan of the grease has been extended by mixing the lubricant with polymer PIB and making it Newtonian.

\subsection{THE SIMPLE AND INTELLIGENT CONTROL OF A MACHINE TOOL'S THERMAL DEFORMATION USING NEURAL NETWORK}

The second example is "THE SIMPLE AND INTELLIGENT CONTROL OF A MACHINE TOOL'S THERMAL DEFORMATION USING NEURAL NETWORK" [34]. As a higher machining precision is required, reducing thermal deformation of the machine tool became a necessity. In this section, a CNC lathe with a simple and intelligence control of thermal deformation using neural network is developed and its precision is evaluated. The neural network was firstly used to determine the relationship between the measured temperatures and the thermal deformation on the lathe. Then, the neural network was written in the form of algebraic equations. Those equations are inserted in the lathe with a PC (Fig. 6). The thermal deformations calculated using the algebraic formula are sent to the data file as correction data. The correction data are then used to automatically correct the thermal deformation using the macro program of the tool wear correction function in the NC as shown in Fig. 7. In fact, a forced cooling device or a linear scale are not needed. The proposed method requires only the addition of a temperature measuring device to a conventional lathe in a high scale precision. Since neither the cooling oil nor the electricity for countermeasure are used, the proposed method is a carbon-neutral countermeasure and can be considered as SDGscompliant approach.

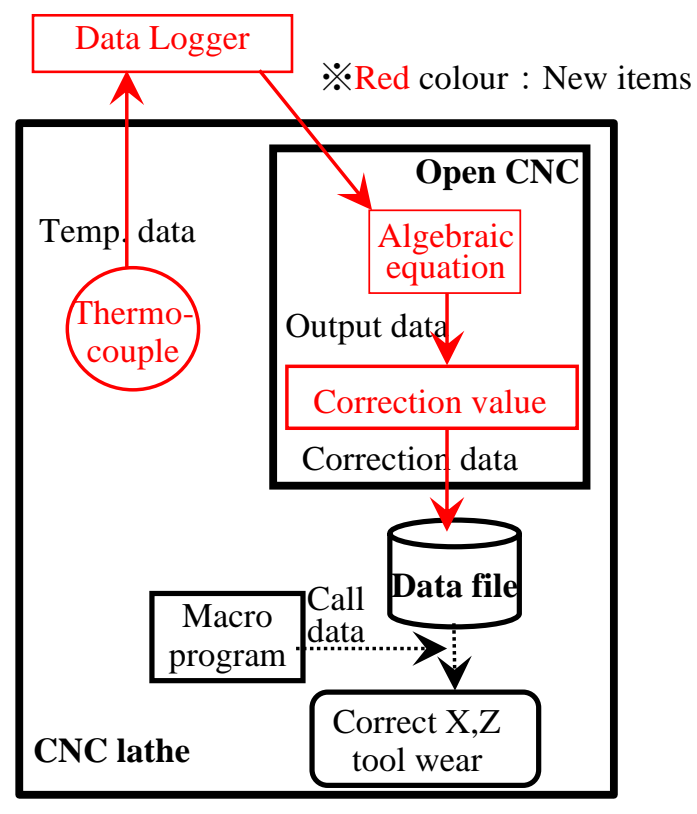

Fig. 6. Schematic view of CNC lathe with thermal deformation control using the algebraic equation which is created by Neural Networks [34]

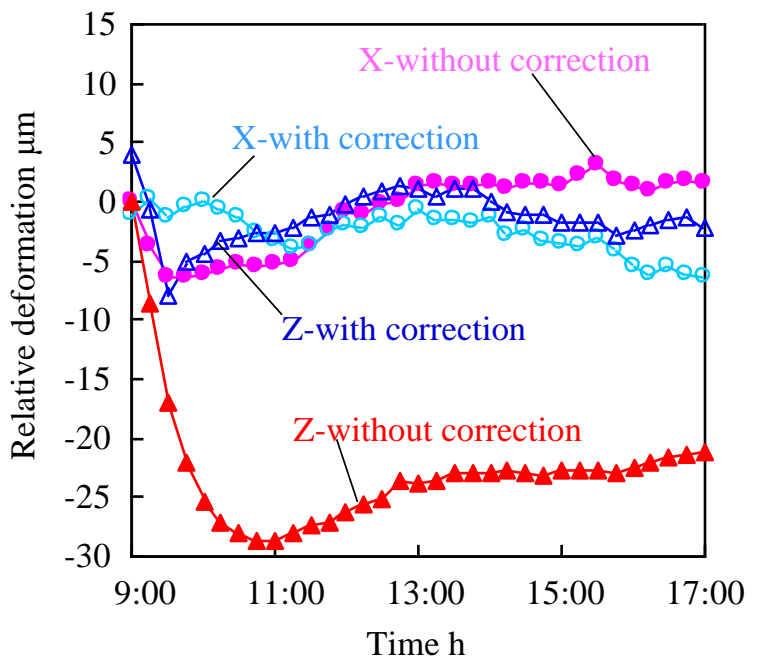

Fig. 7. Results of the thermal deformation control of the CNC lathe using the Neural Networks [34] 


\subsection{THE FORCED COOLING TECHNOLOGY FOR THE TURNING USING DLC COATING TOOL WITH ASMALL HOLE AND COMMUNICATING TUBE}

The third example is "THE FORCED COOLING TECHNOLOGY FOR THE TURNING USING DLC COATING TOOL WITH ASMALL HOLE AND COMMUNICATING TUBE". This example is introduced in this paper. In the turning of the cylindrical workpiece, the tool insert is continuously going into the workpiece and the tempera-ture on the tip of the tool becomes very high. Particularly, when a difficult-to-machine material is used for the workpiece, the temperature reaches the melting point and the tool insert is easily melted. The forced cooling of the tool when it is turning is very difficult. Therefore, in this section, the forced cooling technology using a DLC coating insert with a small hole and a communicating tube is introduced (Fig. 8). In order to provide a cooling function, a small hole was machined at the tip of the insert and strong alkaline water was supplied from the bottom of the insert using the communicating tube. The coefficient of friction is reduced to 0.1 by the DLC layer on the rake face.

The proposed method was evaluated in several experiments; tool's lifespan evaluation, surface roughness of the workpiece after the turning and the $\mathrm{CO}_{2}$ emission estimation. For the experiment, the following cutting conditions were used: speed $=150 \mathrm{~m} / \mathrm{min}$, feed speed $=$ $0.2 \mathrm{~mm} / \mathrm{rev}$, cutting depth $=0.5 \mathrm{~mm}$ and workpiece $=$ carbon steel $(\mathrm{S} 45 \mathrm{C})$. The used parameters are dry, wet, wet and the proposed method.

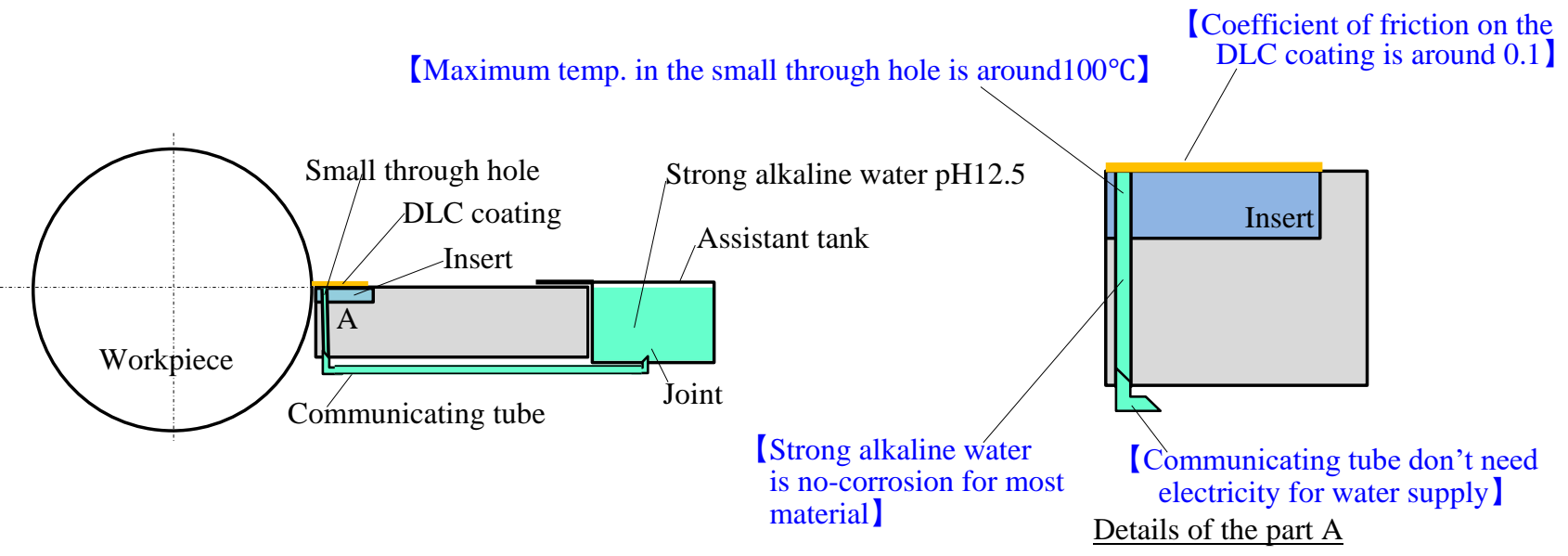

Fig. 8. Explanation the cooling using DLC coating insert with the small hole and the communicating tube

From the results, it is concluded that (1) The proposed forced cooling technology is very effective for the turning as follow in Fig. 9 and Fig. 10, (2) in the proposed method, it is important to maintain the tool tip temperature below $500^{\circ} \mathrm{C},(3)$ the proposed method is more efficient in the $\mathrm{CO} 2$ emission because of the oil- free turning as presented in Fig. 11, (4). The proposed method results in a longer tool's lifespan and better workpiece surface roughness. It is also oil-free and carbon-neutral, what makes it efficient in the achievement of SGDs.

From the experimental results in Sections 3.1 to 3.3, it can be deduced, although without certainty, that it is effective for the SDG 17 shown in Fig. 1. However, this evaluation is not a quantitative approved. 


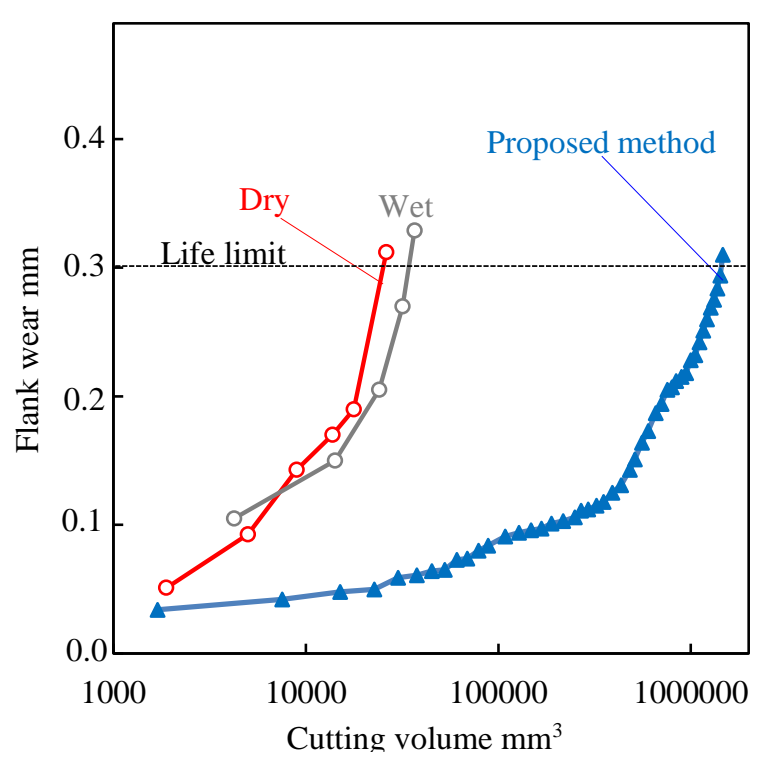

Fig. 9. Experimental results of the tool life for the evaluation of DLC coating insert with the small through hole and the communicating tube. The tool life of the turning using the DLC coating insert with the small through hole was longer than the other turnings

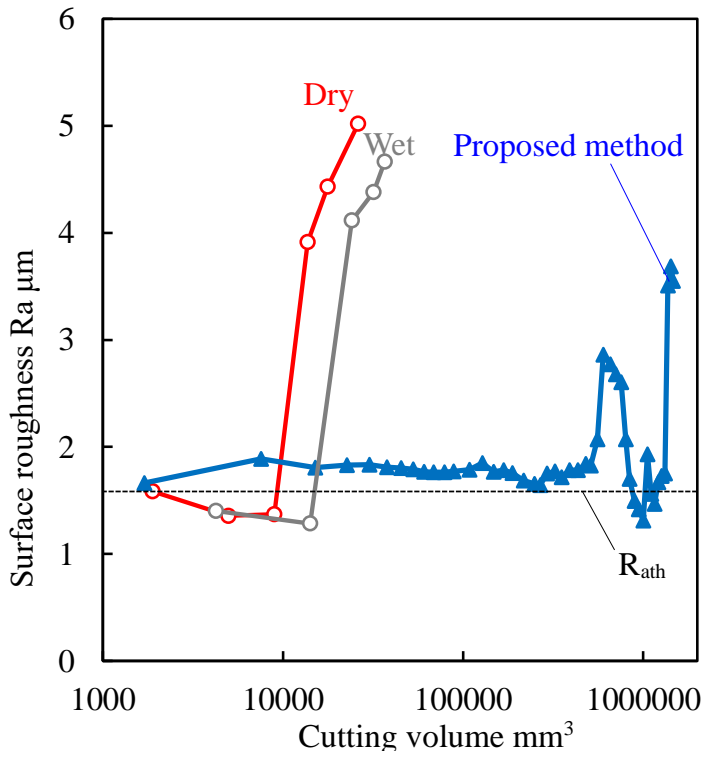

Fig. 10. Experimental results of the surface roughness on workpiece for the evaluation of DLC coating insert with the small through hole and the communicating tube. The surface roughness of the proposed turning was smaller than the other turnings

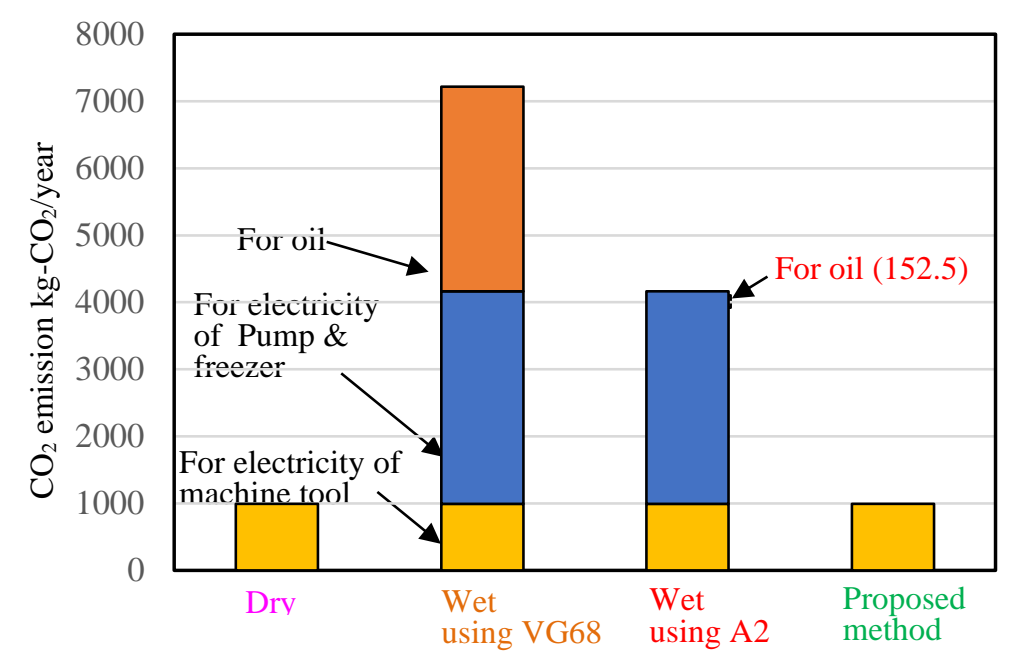

Fig. 11. Evaluation of the proposed method using the LCA. The cutting using the proposed methods results in smaller qualitity of $\mathrm{CO}_{2}$ emission

\subsection{RELATIONSHIP BETWEEN “SDGs" AND THE THREE DEVELOPMENT TECHNOLOGIES}

In this section, the characteristics and effectiveness of the three techniques described in the previous sections were summarized. Their effectiveness for SDGS is discussed, and several methods and indicators to promote SDGS-based manufacturing are considered. 
Table 1. Relationships between "SDGs" and the effectiveness regarding the three examples

\begin{tabular}{|c|c|c|c|c|}
\hline $\begin{array}{l}\text { Section } \\
\text { No. }\end{array}$ & Example titles & \multicolumn{2}{|c|}{ Its Advantages and Benefits } & $\begin{array}{l}\text { Corresponding goals in } \\
\text { "SDGs" }\end{array}$ \\
\hline \multirow{4}{*}{3.1} & \multirow{4}{*}{$\begin{array}{l}\text { Double-rollers } \\
\text { arrangement \& } \\
\text { cost-effective and } \\
\text { eco-friendly } \\
\text { permanent grease } \\
\text { for machine tool } \\
\text { sliders [33] }\end{array}$} & \multicolumn{2}{|c|}{$\begin{array}{l}\text { The lifespan of the developed lubrication method } \\
\text { is } 195 \text { times longer than the lifespan of } \\
\text { conventional lubrication methods. }\end{array}$} & 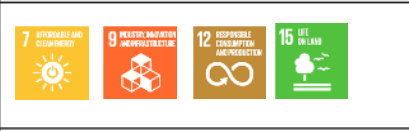 \\
\hline & & \multicolumn{2}{|c|}{$\begin{array}{l}\text { Compared to the conventional method, the } \\
\text { exhaust } \mathrm{CO}_{2} \text { is reduced to } 1 / 88 \text {. }\end{array}$} & 7 (13) \\
\hline & & \multicolumn{2}{|c|}{$\begin{array}{l}\text { The proposed lubrication method was found to } \\
\text { be effective in terms of safety, workability and } \\
\text { economy. }\end{array}$} & 们 \\
\hline & & \multicolumn{2}{|c|}{$\begin{array}{l}\text { The proposed lubrication method did not require } \\
\text { any electricity for control. }\end{array}$} & 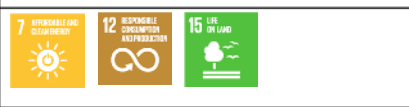 \\
\hline \multirow{4}{*}{3.2} & \multirow{4}{*}{$\begin{array}{l}\text { The simple and } \\
\text { intelligent control } \\
\text { of a machine } \\
\text { tool's thermal } \\
\text { deformation using } \\
\text { neural network } \\
\text { [34] }\end{array}$} & \multicolumn{2}{|c|}{$\begin{array}{l}\text { For the suppression of thermal deformation, the } \\
\text { proposed method requires only the addition of a } \\
\text { temperature measuring device to a conventional } \\
\text { lathe. A forced cooling device or a linear scale } \\
\text { are not needed. }\end{array}$} & 们 \\
\hline & & \multicolumn{2}{|c|}{$\begin{array}{l}\text { The lathe has been converted to a simple AI } \\
\text { system and is capable of machining in a high } \\
\text { scale precision. }\end{array}$} & \& 00 \\
\hline & & \multicolumn{2}{|c|}{$\begin{array}{l}\text { Since neither the cooling oil nor the electricity } \\
\text { are used, the proposed method is a carbon- } \\
\text { neutral countermeasure. }\end{array}$} & 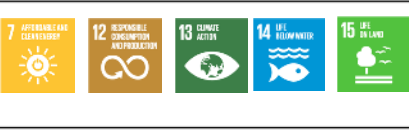 \\
\hline & & \multicolumn{2}{|c|}{$\begin{array}{l}\text { The proposed system was found to be effective } \\
\text { in terms of safety, workability and economy. }\end{array}$} & 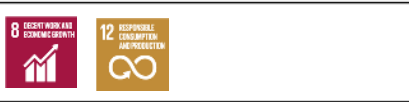 \\
\hline \multirow{5}{*}{3.3} & \multirow{5}{*}{$\begin{array}{l}\text { The forced } \\
\text { cooling } \\
\text { technology using } \\
\text { DLC coating tool, } \\
\text { a small hole and } \\
\text { a communicating } \\
\text { tube for the } \\
\text { turning }\end{array}$} & \multicolumn{2}{|c|}{$\begin{array}{l}\text { The proposed forced cooling presented is very } \\
\text { effective for the turning }\end{array}$} & Q 00 \\
\hline & & \multicolumn{2}{|c|}{$\begin{array}{l}\text { The proposed method is more efficient in the } \\
\mathrm{CO}_{2} \text { emission as well as the dry turning thanks to } \\
\text { the oil- free turning as presented. }\end{array}$} & 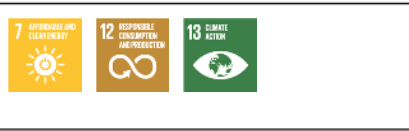 \\
\hline & & \multicolumn{2}{|c|}{$\begin{array}{l}\text { The proposed method results in a longer tool's } \\
\text { lifespan and better workpiece surface roughness. }\end{array}$} & $7=1200$ \\
\hline & & \multicolumn{2}{|c|}{$\begin{array}{l}\text { It is also energy conserving, oil-free and carbon- } \\
\text { neutral }\end{array}$} & 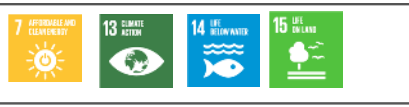 \\
\hline & & \multicolumn{2}{|c|}{$\begin{array}{l}\text { The proposed forced cooling was found to be } \\
\text { effective in terms of safety, workability and } \\
\text { economy. }\end{array}$} & 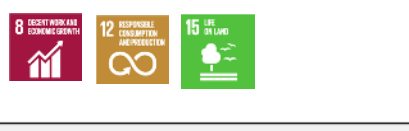 \\
\hline \multicolumn{5}{|c|}{ Icons, numbers and explanations for SDGs } \\
\hline 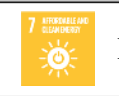 & \multicolumn{2}{|c|}{ No. 7(AFFORDABLE AND CLEAN ENERGY) } & \multicolumn{2}{|c|}{ No. 13(CLIMETE ACTION) } \\
\hline Tิ1 & \multicolumn{2}{|c|}{$\begin{array}{l}\text { No.8 (DECENT WORK AND ECONOMIC } \\
\text { GROWS) }\end{array}$} & \multicolumn{2}{|c|}{ No. 14(LIFE BELOW WATER) } \\
\hline 8 & \multicolumn{2}{|c|}{$\begin{array}{c}\text { No.9 (INDUSTRY, INNOVATION AND } \\
\text { INFRASTRUCTURE) }\end{array}$} & \multicolumn{2}{|c|}{ No. 15(LIFE ON LAND) } \\
\hline $\mathrm{CO}$ & \multicolumn{2}{|c|}{$\begin{array}{l}\text { No.12 (RESPONSIBLE CONSUMPTION } \\
\text { AND PRODUCTION) }\end{array}$} & & \\
\hline
\end{tabular}


After examining the advantages and benefits of the three listed examples and their contribution to the achievement of SDGs, the results are presented in Table 1. Technologies have been developed with higher priority of performance, economy and ecology compared to the conventional technologies. Therefore, there are several advantages and benefits for each example, as shown in Table 1. These advantages and benefits contributed to the achievement of goals No. 7 (AFFORDABLE AND CLEAN ENERGY), No. 8 (DECENT WORK AND ECONOMIC GROWS), No. 9 (INDUSTRY, INNOVATION AND INFRASTRUCTURE), No. 12 (RESPONSIBLE CONSUMPTION AND PRODUCTION), No. 13(CLIMETE ACTION), No. 14(LIFE BELOW WATER) and No. 15(LIFE ON LAND). At this stage, only the relationship between the developed technology and the several goals in SDGs could be ascertained. Some of these advantages and benefits are quantitative items, but there are no quantitative assessments or indicators in relation with the SDGS. In addition, within the 169 targets in the SDGS, there are many items that are difficult to evaluate digitally, items that are extremely complex and non-linear, and items that are synergies or interactions between targets, it is difficult to quantitatively evaluate the benefits and effects of the three case studies directly with each goal of the SDGs. Therefore, as shown in Table 1, it is very difficult to quantitatively assess their contribution to the achievement of the SDGs, although it can be confirmed that they can contribute to the achievement of the SDGs.

\section{QUANTITATIVE EVALUATION USING THE PENTAGONAL W-ECO MODEL FOR MANUFACTURING BASED ON "SDGs"}

In this chapter, the pentagonal W-ECO model [8] is used for the sustainability assessment; this model was proposed in one of the author's previous work. This model will enable quantitative evaluation of manufacturing based on the SGDs, so that sustainable development can be carried out actively and effectively.

First, "Grease lubrication with polymer PIB and W-rollers" (in Section 3.1.) is assessed. As this item has been assessed in previous studies, it will briefly be introduced here. The pentagonal W-ECO model is applied to the proposed lubrication under the best and worst conditions and also to the conventional lubrication. For each case, an evaluation of the five parameters (= Performance, Ecology, Economy, Safety and lifespan) is made separately then, a score from 10 to 100 is assigned to every parameter's evaluation; 100 for the best result, 10 to the worst one and the third value is deduced through a linear calculation. Finally, the results of the evaluation of the five parameters are presented in a radar chart. Here the Recognition Taguchi (RT) of Mahalanobis Taguchi system (MTS) [8], [35] is used in the evaluation of the performances and lifespan. This system excels in the analysis and prediction of complex nonlinear phenomena, complex causal relationships and problems that are difficult to quantify, such as emotions and feelings. The evaluation results [8] using the pentagonal W-ECO model for the proposed lubrication are shown in Fig. 12(a). This discussion is considered after the calculation of the pentagonal W-ECO model for the remaining two examples.

Next, the "Machine tool thermal deformation control using neural networks" and the "Turning using the proposed forced cooling" are respectively evaluated in the Sections 3.2 and 3.3. 
Table 2. Calculation conditions for quantitative evaluation using the pentagonal W-ECO model in Sections 3.2 and 3.3

\begin{tabular}{|c|c|c|c|c|c|c|c|c|c|}
\hline \multirow{2}{*}{ 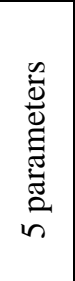 } & \multirow{2}{*}{\multicolumn{2}{|c|}{ DE Category }} & \multirow[b]{2}{*}{ Units } & \multicolumn{3}{|c|}{$\begin{array}{l}\text { Section } 3.2 \text { Control } \\
\text { using neural network. }\end{array}$} & \multicolumn{3}{|c|}{$\begin{array}{l}\text { Section } 3.3 \text { Turing used } \\
\text { forced cooling }\end{array}$} \\
\hline & & & & 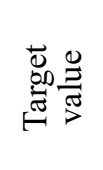 & 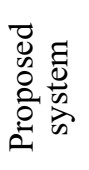 & 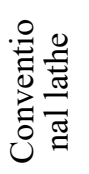 & 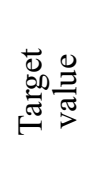 & 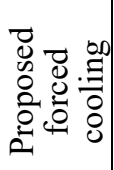 & 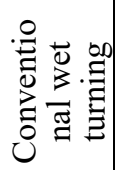 \\
\hline \multirow{11}{*}{ 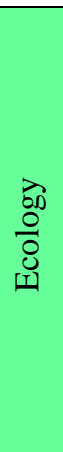 } & \multicolumn{2}{|c|}{ 1. Locality (local-to-local approach) } & $(\mathrm{km})$ & 10 & 10 & 10 & 10 & 10 & 10 \\
\hline & \multicolumn{2}{|l|}{ 2. Renewability } & yes/no/partially & 10 & 10 & 5 & 10 & 10 & 5 \\
\hline & \multicolumn{2}{|c|}{ 3. Durability (Machine and tool lifes) } & (times/year) & 10 & 9 & 5 & 10 & 9 & 1 \\
\hline & \multicolumn{2}{|c|}{ 4. Energy efficiency } & yes/no/partially & 10 & 8 & 3 & 10 & 7 & 2 \\
\hline & \multicolumn{2}{|c|}{ 5. Emissions minimization $\mathrm{CO}_{2}$} & (kg/year) & 10 & 10 & 3 & 10 & 10 & 1 \\
\hline & \multicolumn{2}{|l|}{ 6. Noise / Vibrations } & yes/no/partially & 10 & 10 & 10 & 10 & 10 & 10 \\
\hline & \multicolumn{2}{|l|}{ 7. Waste minimization } & TMR (kg/year) & 10 & 10 & 2 & 10 & 10 & 1 \\
\hline & \multicolumn{2}{|l|}{ 8. By-product safety } & yes/no/partially & 10 & 10 & 10 & 10 & 10 & 10 \\
\hline & \multicolumn{2}{|l|}{ 9. Recyclability } & yes/no/partially & 10 & 10 & 5 & 10 & 5 & 1 \\
\hline & \multirow{2}{*}{\multicolumn{3}{|c|}{$\begin{array}{c}\text { 10. End-of-life waste bioremediation } \\
\text { Total (Data for Table 3) }\end{array}$}} & 10 & 8 & 5 & 10 & 5 & 5 \\
\hline & & & & 100 & 95 & 58 & 100 & 86 & 46 \\
\hline \multirow{7}{*}{ 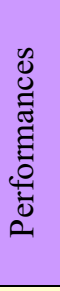 } & \multirow{2}{*}{\multicolumn{3}{|c|}{ Machining accuracy (S.3.2)/Tool Life (S.3.3) }} & \multicolumn{3}{|c|}{ In Fig. 7, $\mu \mathrm{m}$} & \multicolumn{3}{|c|}{ In Fig. $9, \times 10^{3} \mathrm{~mm}^{3}$} \\
\hline & & & & 0 & 4 & 29 & 1500 & 1500 & 12 \\
\hline & \multirow{2}{*}{\multicolumn{3}{|c|}{ formation (S.3.2) }} & \multicolumn{3}{|c|}{ In Fig. $7, \mu \mathrm{m}$} & & Fig. 10 & \\
\hline & & & & 0 & 4 & 29 & 1.6 & 1.6 & 5.0 \\
\hline & Good product rate (S 3 & Exhauct $C O$ & $(\mathrm{~S}, 3.3)$ & & g Fig. & & In Fig. & $1, \times 10^{3}$ & g/year \\
\hline & Soud pioduct rate (3. & Exmatist & (3.J.J) & 100 & 100 & 0 & 750 & 1000 & 7200 \\
\hline & Mahalan & is Distance ( & & 1.31 & 1.28 & 0.01 & 11.8 & 11.8 & 1.00 \\
\hline & 1. Procurement (Usage & es for a mach & e tool) & 5 & 5 & 5 & 5 & 5 & 5 \\
\hline & 2.Manufacturing and se & p (Labour co & & 57 & 57 & 57 & 57 & 57 & 200 \\
\hline$\widehat{\Xi}$ & 3.Operation (Disposal & waste and de & ctive products) & 2 & 2 & 10 & 2 & 2 & 10 \\
\hline ̊̆ & 4.Utilities (Equipme & d devices) & & 0 & 0.1 & 0 & 0 & 0 & 0.1 \\
\hline 包 & 5.Consumables (tool, & tricity, oil) & & 3 & 3 & 11 & 3 & 3 & 11 \\
\hline & 6.Maintenance and arr & ements & & 0 & 0 & 50 & 0 & 0 & 100 \\
\hline & Total Cost & nit: $\times 10^{3}$ USI & /year) & 67 & 67 & 133 & 67 & 67 & 326 \\
\hline & & 1. Acute ora & toxicity & 10 & 9 & 9 & 10 & 9 & 9 \\
\hline & & 2. Acute der & hal toxicity & 10 & 9 & 9 & 10 & 9 & 9 \\
\hline. & Human Helth Riskc & 3. Acid burr & & 10 & 9 & 9 & 10 & 9 & 9 \\
\hline 80 & Human Health Kisks & 4. Skin effec & & 10 & 9 & 9 & 10 & 9 & 9 \\
\hline 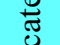 & & 5. Respirato & effects & 10 & 9 & 9 & 10 & 9 & 9 \\
\hline$\frac{y}{n}$ & & 6. Internal e & ects & 10 & 9 & 9 & 10 & 9 & 9 \\
\hline 2 & Environmental Risks & 7. Greenhou & e Gas Pot & 10 & 9 & 1 & 10 & 9 & 1 \\
\hline 5 & & 8. Resource & carcity & 10 & 9 & 1 & 10 & 9 & 1 \\
\hline 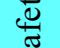 & Business Risks & 9. Price esci & ation & 10 & 9 & 1 & 10 & 9 & 1 \\
\hline & & 10. Trust & & 10 & 9 & 1 & 10 & 9 & 1 \\
\hline & & Total & & 100 & 90 & 58 & 100 & 90 & 58 \\
\hline & & melts $\left(\mathrm{S}_{3}\right.$ ? & and $32,+3<>$ & Usir & Fig. 7, & ears & In Fig & 9 and 10 & years \\
\hline & Life of machine tool us & $g$ melts (S.3.2 $)$ & and 3.3 ) & 25 & 20 & 5 & 25 & 20 & 5 \\
\hline & I ife of tool using tool & recults $\left(\mathrm{C}_{2}\right.$ & on & Usi & Fig. 7 & & & Fig. $9, \mathrm{~m}$ & \\
\hline क्षे & Lile or toor using toor & Iesuits (3.J. & and 3.5$)$ & 10 & 10 & 10 & 1500 & 1500 & 12 \\
\hline$\Xi$ & L ife of technolooy usi & exhaust $\mathrm{CO}_{2}$ & 32 and 33$)$ & [34] an & eq. $(1)($ & years & Usin & Fig. 11, & years \\
\hline & 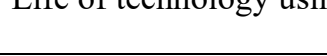 & Anaust $\mathrm{C}_{2}$ & (1) & 15 & 10 & 1 & 15 & 10 & 1 \\
\hline & Mahalar & is Distance ( & ID) & 1.0 & 0.7 & 0.03 & 28.0 & 28.0 & 0.01 \\
\hline
\end{tabular}


Table 3. Indices for the pentagonal W-ECO model of each technology for Sections 3.2 and 3.3. DE Index $(\%)=($ Real implementation) / (Ideal implementation); The DE Index consists on a dimensionless index that combines all the mentioned evaluations and allows to compare them to the ideal results [8]. ( ): Data in Table 2

\begin{tabular}{|c|c|c|c|c|c|c|c|c|}
\hline $\begin{array}{l}\text { Zz } \\
\text { :0 }\end{array}$ & Technology & Ecology & $\begin{array}{l}\text { Perfor- } \\
\text { mances }\end{array}$ & Economy & Safety & Lifespan & $\begin{array}{c}\text { Calculated } \\
\text { area }\left(\mathrm{u}^{2}\right)\end{array}$ & $\begin{array}{c}\text { DE Index } \\
(\%)\end{array}$ \\
\hline \multirow{6}{*}{$\stackrel{\sim}{\sim}$} & \multirow[t]{2}{*}{ Target value } & 100 & 100 & 100 & 100 & 100 & \multirow{2}{*}{23800} & \multirow{2}{*}{100} \\
\hline & & $(100)$ & $(1.31)$ & (67) & $(100)$ & $(1.0)$ & & \\
\hline & \multirow{2}{*}{ Proposed system } & 89 & 98 & 100 & 80 & 72 & \multirow{2}{*}{18400} & \multirow{2}{*}{77} \\
\hline & & $(95)$ & $(1.28)$ & (67) & $(90)$ & $(0.7)$ & & \\
\hline & \multirow[t]{2}{*}{ Conventional lathe } & 10 & 10 & 10 & 10 & 10 & \multirow{2}{*}{238} & \multirow{2}{*}{1} \\
\hline & & $(58)$ & $(0.01)$ & (133) & $(58)$ & $(0.03)$ & & \\
\hline \multirow{6}{*}{$\ddot{m}$} & \multirow[t]{2}{*}{ Target value } & 100 & 100 & 100 & 100 & 100 & \multirow{2}{*}{23800} & \multirow{2}{*}{100} \\
\hline & & $(100)$ & $(11.8)$ & (67) & $(100)$ & (28) & & \\
\hline & \multirow[t]{2}{*}{ Proposed forced cooling } & 77 & 100 & 100 & 80 & 100 & \multirow{2}{*}{19700} & \multirow{2}{*}{83} \\
\hline & & (86) & $(11.8)$ & (67) & $(90)$ & (28) & & \\
\hline & \multirow[t]{2}{*}{ Conventional wet turning } & 10 & 10 & 10 & 10 & 10 & \multirow{2}{*}{238} & \multirow{2}{*}{1} \\
\hline & & (46) & $(1.0)$ & (326) & $(58)$ & $(0.01)$ & & \\
\hline
\end{tabular}

The calculation conditions for the quantitative evaluation using the pentagonal W-ECO model are given in Table 2. In the "Ecology", Fig. 7 and Reference [33] in Section 3.2 and Fig. 9, Fig. 10 and Fig. 11 in Section 3.3 were used for the evaluation of 3: Durability, 4: Energy efficiency and 5: Emissions minimization respectively in Table 2. For the other items in "Ecology", The general machine life, tool life, running costs per year, recyclability of machines and technology, durability, environmental impact and waste characteristics and impacts are discussed and evaluated in Sections 3.2. and 3.3. For "Performances" in Section 3.2., Machining accuracy, Thermal deformation and Good product rate are evaluated using Fig. 7 and Reference [33], and Tool Life, Surface roughness and Exhaust $\mathrm{CO}_{2}$ are evaluated using Figs. 9, 10 and 11 in Section 3.3. RT method of MT system is used for the analysis. The data of the conventional system is used for the unite space of the RT method, the Mahalanobis Distance (MD) of the target value and the proposed system are calculated using the unite space of the conventional system. For "Economy", in section 3.1, a machine tool in operation for one year, procurement, manufacturing and setup, operation, utilities, consumables and maintenance are calculated using results from Fig. 7 and Reference [33] in Section 3.2 and Fig. 9, Fig. 10 and Fig. 11 in Section 3.3. For "Safety", Fig. 7 in Section 3.2 and Fig. 10 in Section 3.3 regarding environmental risks are used for the evaluation. For the other items in "Safety", as in section 3.1, have been evaluated for proposed system and forced cooling regarding the general human health risks and business risks in Sections 3.2 and 3.3 have been considered and evaluated. In "Lifespan", machine tool life, tool life and technology life in both Sections 3.2 and 3.3 were evaluated using the Figs. 7, 9, 10, 11, Reference [33] and equations (1) and (2). The RT method of the MT system is used for analysis. The data of the conventional wet turning is used for the unite space of the RT method, the Mahalanobis Distance (MD) of the target value and the proposed forced cooling is calculated using the unite space of the conventional wet turning. 


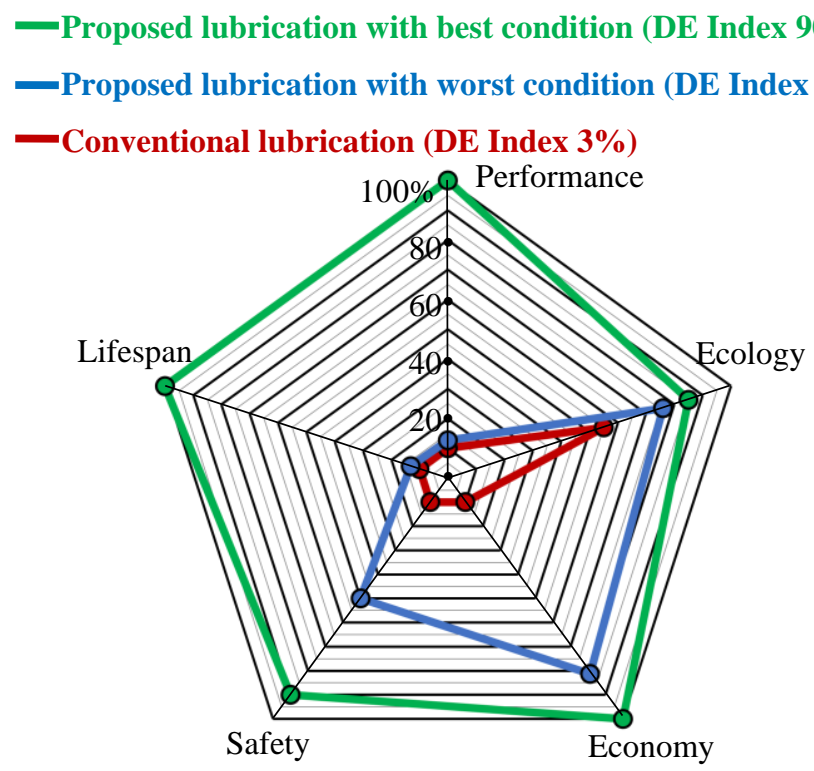

(a) Section 3.1. Grease lubrication with polymer PIB and $\mathrm{W}$ rollers [8]
- Target value (DE Index 100\%)

Proposed system (DE Index 77\%)

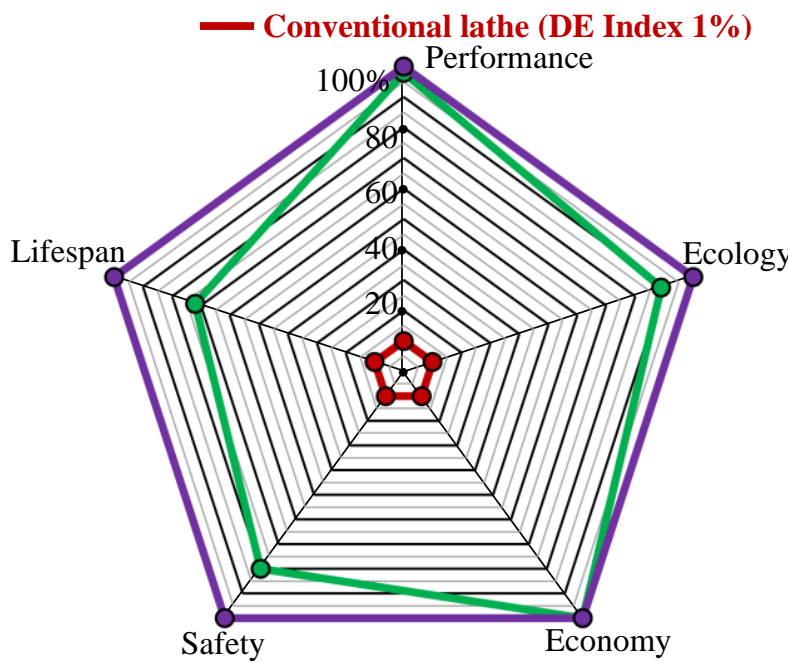

(b) Section 3.2. Machine tool thermal deformation control using neural networks

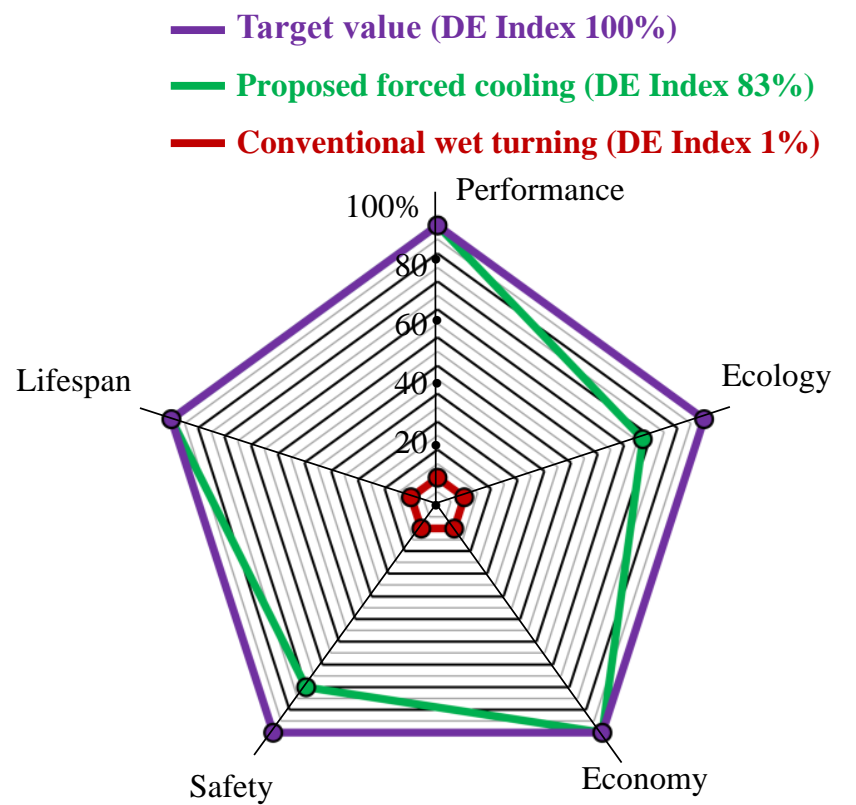

(c) Section 3.3. Turning using the proposed forced cooling

Fig. 12. Results of the new DE evaluation for each technology using pentagonal W-ECO model

Using the calculation conditions shown in Table 2 and following reference [8], as in Section 3.1, two indexes for the pentagonal W-ECO model of each technology in Sections 3.2 and 3.3. are in Table 3. Table 3 have been calculated by using the data in Table 2; a score from 10 to 100 is assigned to every parameter's evaluation; 100 for the target value, 10 to the conventional matter and the proposed technology is deduced through a linear calculation.

Results of the quantitative evaluation with the pentagonal W-ECO model are shown in Figs. 12(b) and 12(c), respectively. In Fig. 12(a), the quantitative contribution of the proposed 
grease to the achievement of the SDGs can be grasped. The visual representation provides an easy quantitative and comprehensive evaluation. This evaluation method shows that the proposed lubrication system can be evaluated differently depending on the operating conditions. In Fig. 12(b) and Fig. 12(c), the extent to which the proposed system or method improves on the target values and the extent of the current development are quantitatively, visually, and comprehensively shown. This information and analysis is extremely useful for the subsequent development and manufacturing of the SGDs.

The pentagonal W-ECO model was able to provide useful quantitative, visual, and comprehensive evaluation information for three different manufacturing technologies. The five parameters of pentagonal W-ECO model used in the evaluation are closely related to the SDGs No. 7, 8, 9, 12, 13, 14 and 15, respectively. Traditionally, only both performance and economics have been emphasized and are these were only and extremely important for improving the sustainability of a manufacturer. Ecology, risk management, and lifespan, as discussed throughout this paper, are important factors not only for environmental protection

but also for SDGs-based manufacturing and SDGs achievement. This is particularly important for achieving the SDGs 7, 8, 9, 12, 13, 14, and 15 shown in Table 1. Quantitative evaluation using the pentagonal W-ECO model is important for the SDGs and for the survival and development of manufacturers. In fact, quantitative evaluation using the pentagonal W-ECO model at the development stage not only makes the development target values extremely clear, but also enables the active development of sustainability for the Earth, humans, and manufacturers. The quantitative evaluation through the pentagonal W-ECO model includes many extremely complex nonlinear relationships such as human emotion, reason, and sensibility, and in this paper, the MT system (RT method) [35] is used to deal with them in "Performances" and "Lifespan". In order to improve the estimation accuracy of the quantitative evaluation of the actual analysis and prediction using the pentagonal W-ECO model, Mahalanobis Distance (MD) in the MT system (RT method) should be set using the results of multiple analysis and predictions. The W-ECO model was basically a triangular model (performance, economy, and ecology) and has now evolved into a pentagonal model (performance, economy, and ecology, safety and lifespan). In the future, if the evaluation target changes in the SDGs, or if there is an increase or decrease in the number of SDGs, as the $\mathrm{W}$-ECO model has evolved from a triangular model to a pentagonal model, it will be possible to adjust and upgrade the parameters of the W-ECO model. In addition, the use of MT system (RT method) is effective for parameters that are difficult to evaluate quantitatively.

The currently proposed pentagonal W-ECO model corresponds to SDGs 7, 8, 9, 12, 13, 14 and 15, but not to all 17 goals, as shown in Table 1. Therefore, my future work is to evolve the W-ECO model into hexagons, octagons and dodecagons, and to propose a quantitative evaluation tool to simultaneously achieve the 17 goals of the SDGs.

\section{CONCLUSION}

In this paper, use of the Pentagonal W-ECO model as a quantitative evaluation method for manufacturing based on the SDGs was proposed and proved to be effective. The conclusions are the following. (1) Using the life span of a computer as an example, the importance 
of extending the life span of industrial products for resource conservation and manufacturing based on the SDGs is clarified, and the necessity of "regeneration" technology is clarified for this purpose. (2) After explaining the author's three past research examples, the relationship between these technologies and the SDGs was discussed, and the necessity for manufacturing based on the SDGs was considered and discussed. (3) Using the W-ECO model in his previous research, the three research examples were quantitatively evaluated, and the effectiveness of the pentagonal s a quantitative evaluation method for manufacturing based on the SDGs was cleared.

\section{REFERENCES}

[1] Ministry of Foreign Affairs, Retrieved on February 19th 2021, https://www.mofa.go.jp/mofaj/gaiko/oda/sdgs/ index.html.

[2] Imacocollabo, Retrieved on February 19th 2021, https://imacocollabo.or.jp/about-sdgs/17goals/.

[3] MARINOVA D., ANNANDALE D., PHILliMORE J., 2006, The International Handbook on Environmental Technology Management, Edward Elgar Publishing, Inc., United Kingdom.

[4] TANABE I., 2016, Double-ECO Model Technologies for and Environmentally Friendly Manufacturing, Procedia CIRP, 23rd CIRP Conference on Life Cycle Engineering, 48, 495-501.

[5] SALING P., KICHERER A., DITTRICH-KRÄMER B., et al., 2002, Eco-Efficiency Analysis by BASF: The Method, The International Journal of Life Cycle Assessment, 7/4, 203-218.

[6] TANABE I., 2017, Consideration Regarding Environmentally-friendly in Manufacturing Field, Proceedings of the 2nd World Congress on Civil, Structural and Environmental Engineering (CSEE-17), ICESDP 104, 1-10.

[7] PENA-GONZALEZ L.E., DA SILVA P., TANABE I., 2018, Development of Environmentally Friendly Technologies Based on Double Eco Model - An Evaluation Platform, Journal of Machine Engineering, 18/1, $18-31$.

[8] LABIDI A., TANABE I., TAKAHASHI S., 2021, A Study on Extending Technologies Lifespan for the Environment Safety, Journal of Machine Engineering, 21/1, 109-120.

[9] MOURTZIS D., DOUKAS., M., 2014, The Evolution of Manufacturing Systems: From Craftsmanship to the Era of Customization, Handbook of Research on Design and Management of Lean Production Systems, IGI Global, 1-29.

[10] ELMARAGHY H., MONOSTORI L., SCHUH G., ELMARAGHY W., 2021, Evolution and Future of Manufacturing Systems, CIRP Annals, 70/2, 635-658.

[11] DIMITRIS M., 2020, Simulation in the Design and Operation of Manufacturing Systems: State of The Art and New Trends, International Journal of Production Research, 58/7, 1927-1949,

[12] FOIVOS P., GÖKAN M., PAUL-ARTHUR D., DIMITRIS K., 2020, Zero Defect Manufacturing: State-of-The-Art Review, Shortcomings and Future Directions in Research, International Journal of Production Research, 58/1, 1-17.

[13] MOURTZIS D., ANGELOPOULOS J., PANOPOULOS N., 2021, Equipment Design Optimization Based on Digital Twin Under the Framework of Zero-Defect Manufacturing, Procedia Computer Science, 180, 525-533.

[14] MOURTZIS D., DOUKAS M., PSAROMMATIS F., (2013). Environmental Impact of Centralised and Decentralised production Networks in The Era of Personalisation, Robust Manufacturing Control, Springer, Berlin, Heidelberg, 371-384.

[15] OLAH J., ABURUMMAN N., POPP J., KHAN M.A., HADDAD H., \& KITUKUTHA N., 2020, Impact of Industry 4.0 on Environmental Sustainability. Sustainability, 12/11, 46-74.

[16] BURRITT R., CHRIST K., 2016, Industry 4.0 and Environmental Accounting: A New Revolution?, Asian Journal of Sustainability and Social Responsibility, 1/1, 23-38.

[17] LEBEL S., 2016, Fast Machines, Slow Violence: Icts, Planned Obsolescence, and E-Waste, Globalizations, 13/3, 300-309.

[18] SIRAIT M., BISWAS W., BOSWELL B., 2012, Personal Computer Life Cycle Assessment Study: The Case of Western Australia, Proceedings:10th Global Conference on Sustainable Manufacturing, 277-280.

[19] BABBITT C.W., KAHHAT R., WILliAMS E., BABBITT G.A., 2009, Evolution of Product Lifespan and Implications for Environmental Assessment and Management: A Case Study of Personal Computers in Higher Education, Environmental Science \& Technology, 43/13, 5106-5112.

[20] AHLUWALIA P.K., NEMA A.K., 2007, A Life Cycle Based Multi-Objective Optimization Model for the Management of Computer Waste, Resources, Conservation and Recycling, 51/4, 792-826. 
[21] YOSHIDA A., TASAKI T., TERAZONO A., 2009, Material Flow Analysis of Used Personal Computers in Japan, Waste Management, 29/5, 1602-1614.

[22] WILlIAMS E., 2004, Energy Intensity of Computer Manufacturing: Hybrid Assessment Combining Process and Economic Input - Output Methods, Environmental Science \& Technology, 38/22, 6166-6174.

[23] WILliAMS E., HATANAKA T., 2005, Residential Computer Usage Patterns in Japan and Associated Life Cycle Energy Use, Proceedings of the 2005 IEEE International Symposium on Electronics and the Environment, $177-182$.

[24] AL RAZI K.M.H., 2016, Resourceful Recycling Process of Waste Desktop Computers: A Review Study, Resources, Conservation and Recycling, 110, 30-47.

[25] HOANG A., TSENG W., VISWANATHAN S., EVANS H., 2009, Life Cycle Assessment of a Laptop Computer and its Contribution to Greenhouse Gas Emissions, Researchgate.net.

[26] CORTES M.A., PATINO M.L.D., RUIZ N.L., VACA L.E. M., 2016, Importance of Life Cycle Analysis of the Printed Circuit Board Computer, Open Journal of Applied Sciences, 6/1, 1-6.

[27] KUEHR R., WILLIAMS E., 2003, Computers and the Environment: Understanding and Managing their impacts: Understanding and Managing Their Impacts, Springer, ISBN: 978-94-010-0033-8.

[28] Ministry of Economy, Trade and Industry, Retrieved on October 27th 2021, https://www.meti.go.jp/policy/recycle/ main/english/pamphlets/index.html

[29] e-Gov, Ordinance related to calculation for carbon dioxide equivalent greenhouse gas emissions with their business activities of specified emitters, 2010, Article 2, http://elaws.e-gov.go.jp/search/elawsSearch/elaws_search/lsg0500 /detail?lawId=418M60001400003, (in Japanese).

[30] Ministry of the environment, Announcement of actual emission factor, adjusted emission per electric utility company in FY 2017, 2018, Retrieved on April 23th 2019, http://www.env.go.jp/press/files/jp/110465.pdf, (in Japanese).

[31] Ministry of the environment, Calculation method and emission factor on calculation, report and publication system, 2015, Retrieved on April 23th 2019, http://ghg-santeikohyo.env.go.jp/ files/calc/itiran2015.pdf, (in Japanese).

[32] Greenhouse gas inventory office of Japan, National Greenhouse Gas inventory Report of JAPAN, 2019, Retrieved on April 15th 2019, http://www-gio.nies.go.jp/aboutghg/nir/2019/NIR-JPN-2019-v3.0_J_GIOweb.pdf, (in Japanese).

[33] TANABE I., WATANABE M., 2011, Development of Cost-effective and Eco-friendly Permanent Grease Lubrication for the Machine Tool Slides, 2011 IEEE International Symposium on Assembly and Manufacturing (ISAM).

[34] TANABE I., KANAKO Y., SAITOH Y., MORI H., URANO K., 2004, Simple and Intelligent Control Using Neural Network About Thermal Deformation of a Machine Tool, Transactions of the Japan Society of Mechanical Engineers, 70/698, 2954-2960, (in Japanese).

[35] SUZUKI M., 2012, Introduction to Analysis Method Using MT System, Nikkankougyoushinbunsya, (in Japanese). 